\title{
PRESAGIOS, PRODIGIOS O TETZÁHUITL DE LA CONQUISTA DE MÉXICO: UNA APROXIMACIÓN HISTÓRICA Y RITUAL
}

\author{
OMENS, PRODIGIOUS OR TETZAHUITL \\ OF THE CONQUEST OF MEXICO: \\ A HISTORICAL AND RITUAL APPROACH
}

\author{
Manuel A. Hermann Lejarazu \\ CIESAS-CDMX \\ hermann@ciesas.edu.mx
}

\begin{abstract}
Given the enormous interest that the study of omens or tetzahuitl linked to the Conquest Mexico has aroused, this article seeks to correlate the internal meaning of the tetzahuitl not as an omen, but as the manifestation of the fears that the individual suffered when facing a prodigious phenomenon. In this way, the prodigies that gave rise to the divine presence in two different contexts will be analyzed: the prodigy in ancient Rome of the Republic period and the tetzahuitl in the great Tenochtitlan of the early 16th century.
\end{abstract}

Keywords: tetzahuitl, prodigy, expiation rituals, Conquest of Mexico.

\section{Resumen}

Dado el enorme interés que ha despertado el estudio de los presagios o tetzáhuitl vinculados a la Conquista de México, el presente artículo busca correlacionar el sentido interno del tetzáhuitl no como un signo de augurio, sino como la manifestación de los temores y miedos que experimentaba la persona al estar frente a un fenómeno prodigioso. De esta manera se analizarán los prodigios que dieron origen a la presencia divina en dos contextos diferentes, el prodigio en la antigua Roma del período de la República y el tetzáhuitl en la gran Tenochtitlan de principios del siglo XVI.

Palabras clave: tetzáhuitl, prodigio, rituales de expiación, conquista de México. 


\section{Introducción}

Hoy en día, la mayoría de los interesados en el tema de la Conquista de México conocen, o les resulta fácil percatarse, de la abundante literatura que se ha generado en torno a los presagios (o el conjunto de augurios funestos) que supuestamente se presentaron no sólo en la antigua ciudad de México-Tenochtitlan sino también en otras áreas de Mesoamérica, tal y como parece registrarse en diversas fuentes etnohistóricas. En efecto, de acuerdo con algunos textos, estos sucesos extraños parecen haber ocurrido tanto en las tres cabeceras del gran señorío purhépecha del Occidente de México, así como también entre grupos cazcanes, tepehuanos y diversos pueblos nahuas de esta misma región; a su vez, existe constancia de los registros proféticos recopilados en los libros de Chilam Balam en Yucatán $y$, de acuerdo con algunos historiadores indígenas, tales prodigios se manifestaron en otros señoríos nahuas como Tlaxcala, Chalco o Tetzcoco.

Es probable que los presagios, cuyos mensajes aparentemente antecedieron a la Conquista, tuvieran presencia en varias partes de México más bien como un tipo de género discursivo que no solamente fijaba su atención en los eventos ocurridos de manera extraordinaria, sino también recopilaban testimonios sobre el impacto que producía el prodigio en el ánimo de los diversos sectores de la población, ya fuera desde el máximo gobernante hasta la población común en general. Por ello, los presagios registrados en las fuentes históricas del siglo XVI pueden llegar a entenderse como una serie de relatos elaborados o construidos para evocar la imaginería de todos aquellos que no presenciaron tales eventos, aunque es interesante mencionar que no existen registros de augurios o premoniciones en el mundo mixteco o zapoteco, ni tampoco en algún otro pueblo de habla otomangue.

Desde luego, los prodigios que tuvieron su aparición en Tenochtitlan no fueron exactamente iguales a todos los demás que se observaron en diferentes partes o, inclu- so, de los que se registraron en el propio reino purhépecha, pero hay una serie de elementos comunes que son compartidos entre este tipo de expresiones que pueden ser valorados desde una perspectiva más universal o también enteramente mesoamericana. El fenómeno del prodigio, o la manifestación de sucesos poco habituales en la vida cotidiana, rompe el orden natural de las cosas, ocurre de manera imprevista y dependiendo del sistema de creencias del grupo humano en particular que lo percibe, éste puede llegar a ser considerado un infortunio o, incluso, todo lo contrario.

Considerando que los grupos indígenas mesoamericanos tuvieron una relación estrecha con lo sagrado, es factible dar crédito a los textos indígenas registrados en el Códice florentino, por ejemplo, cuando hablan del temor, angustia o aflicción que despertó entre los pobladores la aparición de los tetzáhuitl durante la última década del señorío de Motecuhzoma Xocoyotzin. No obstante, algo que puede llegar a desconcertarnos, sobre todo en una sociedad tan profundamente religiosa como la mexica, es la total ausencia de rituales o ceremonias de expiación que intentaran atajar o conjurar, de algún modo, el nefasto presagio que se levantaba ante sus ojos.

En efecto, no existe ningún texto en el libro XII de Sahagún que registre alguna suerte de ritual o ceremonia propiciatoria que buscara conjurar los prodigios que se cernían sobre la gran Tenochtitlan, situación que también pasa desapercibida en las crónicas o escritos históricos de otros religiosos como Motolinía, Durán, Torquemada o Acosta, pues si bien todos ellos documentan también prodigios y portentos que anunciaban el final de los tiempos, nadie menciona que se hubieran efectuado importantes rituales expiatorios que buscaran impedir los designios que anunciaban un fatal desenlace. ¿A qué se debe esta situación? ¿Acaso estamos ante una carencia de rituales expiatorios frente a los augurios? ¿O la actitud ante los presagios es completamente distinta en Mesoamérica a diferencia de otros pueblos en los que se daba prioridad 
al ceremonial que buscaba conjurar el prodigio? Si aparentemente el mundo mesoamericano estaba en contacto permanente con el universo sagrado y sus diversas manifestaciones, ¿por qué iban a ser vistos de manera diferente los presagios de la Conquista? ¿Qué tuvieron éstos de especiales si, hasta donde sabemos, el mundo nahua, por ejemplo, estaba consciente y habituado a los fenómenos físicos como manifestaciones de lo sagrado?

Si bien coincido con el hecho de que los tetzáhuitl son recursos explicativos acerca de la concepción cíclica del tiempo, del devenir y de la naturaleza divina (Ledesma Bouchan, 2019: 13), pienso que, para su redacción final, tal y como aparecen en los textos históricos, los presagios transitaron por diversas etapas de construcción, en las cuales se llegó a pasar por alto un elemento ritual de suma importancia en el carácter y función de los augurios: la expiación o la conjuración de estos mismos. Por esta razón, pienso que la composición del tetzáhuitl, por lo menos en su versión escrita para el libro XII de Sahagún, carece de este elemento fundamental que sí está presente en otros libros del propio franciscano, como el libro V, por ejemplo, "Que trata de los agüeros y prenósticos que estos naturales tomaban de algunas aves, animales y sabandixas para adivinar las cosas futuras" (Sahagún, 2000: t. 1, 433-469).

Por lo tanto, mi intención es contribuir, a lo largo del presente artículo, con nuevos elementos de análisis para comprender mejor la historicidad del tetzáhuitl (en su dimensión específica de presagio de la Conquista) como una construcción a posteriori, en la que confluyen concepciones indígenas y elementos novedosos creados a partir de las secuelas de la guerra de conquista. Además, pienso que no hay que desdeñar el papel de los frailes como recopiladores de estos discursos, pues ellos formaban parte de la herencia europea en torno a los augurios y prodigios que provenían de tradiciones tan antiguas como, incluso, las romanas.

De esta manera, primero procederé a un análisis de los términos principales que in- titulan al presente artículo para después, a través de un método comparativo, hacer una revisión sobre el tratamiento ritual a los augurios y prodigios que realizaban sociedades no mesoamericanas, para compararlos, finalmente, con los métodos empleados en el México indígena ante la presencia de un presagio.

\section{Tetzáhuit/: ¿augurio, presagio o prodigio?}

Como es bien sabido, los augurios han tenido una enorme repercusión en el ámbito interpretativo de los modernos historiadores que aún mantienen intensos debates sobre la veracidad, simbología, significado, valor autóctono o importado de estos relatos que de algún u otro modo condicionan la comprensión del fenómeno de la Conquista de México. Autores contemporáneos como León-Portilla (1991), Carrasco (2000), Aimi (2009), Olivier (2006, 2019), Graulich (2014), Elliot (2010), Pastrana Flores (2009), Johansson (2013), Alcántara (2019), Magaloni (2016) o Rozat Dupeyron (2002) han llevado a cabo muy interesantes análisis sobre la importancia de estos registros.

Por razones de espacio, no es posible discutir aquí los trabajos de cada uno de ellos, pero brevemente podemos señalar que para Aimi, por ejemplo, los presagios son "una reelaboración de versiones indígenas primitivas que Sahagún reagrupa y extrae de su contexto originario, probablemente de tipo narrativo" (2009: 84). Según este autor, quien intenta interpretar los presagios no sólo de Sahagún sino también los que se encuentran en las obras de Durán, Tezozómoc y en algunas otras fuentes, los augurios evocan símbolos cosmológicos que pueden rastrearse en los relatos míti$\cos$ y en los elementos propios de la religión mexica, de manera que los presagios entran en el ritmo de la concepción cíclica del tiempo y en las sucesivas eras cuyos cataclismos anunciaban la llegada de una nueva etapa (Aimi, 2009: 137-141). Para Carrasco (2000: 187-191), los presagios son parte de una crisis que venía ocurriendo en los 
primeros años del siglo XVI, por lo que las apariciones de señales en el cielo fueron vistas por los mexicas como una comunicación cosmológica que refleja el destino del Quinto Sol. Los presagios, entonces, aparecieron como mensajes de destrucción, un cambio en el estado de las cosas y el anuncio sobre el final de un imperio.

Según Graulich (2014: 240), las profecías pueden distinguirse en dos grupos: las que tienen marca española destinadas a justificar la Conquista, y las de origen mexica, que básicamente anuncian los eventos o buscan explicar el porqué de la derrota. Las del segundo grupo, anota este mismo autor (2014: 244), si bien comparten elementos con otras premoniciones o señales bien documentadas en otras partes del mundo como, por ejemplo, en Jerusalén o en Roma, algunos de los presagios indígenas están mejor estructurados y estrechamente ligados a concepciones mexicas sobre el mundo y la historia. De manera que para Graulich (2014: 246-247), presagios como la famosa lista de "los ocho" del libro XII de Sahagún, muestran la naturaleza dual del universo nahua prehispánico; en cambio para Rozat Dupeyron (2002: 137), los textos indios de la conquista están inmersos en una simbología ajena al pasado indígena prehispánico, pues obedecen a un modelo cristiano y medieval.

Por otro lado, también contamos con interpretaciones históricas sobre el origen de los presagios, como Martínez Baracs (1998) o Elliot (2010). Martínez Baracs (1998: 2933), por ejemplo, ofrece una interesante perspectiva al señalar que los encuentros previos y fortuitos entre náufragos y viajeros europeos con grupos mayas desde 1502 y hasta 1518, bien pudieron ser una rica fuente de información que sirvió de materia prima fundamental para la creación de los presagios que fueron, según el mismo autor, "una manera mediante la cual, la presencia española se transmitió mitologizada en las distintas capas y regiones de Mesoamérica [...]". Para Elliot (2010: 220-224), en cambio, los presagios son una lectura retrospectiva de las consecuencias de la guerra de conquista que derrocó a los antiguos dioses y al imperio mexica que los adoraba. Este autor sostiene que los presagios del Códice florentino guardan sorprendentes similitudes con los registrados en autores clásicos del mundo occidental, cuyas obras se encontraban en la biblioteca del Colegio de Santa Cruz de Tlatelolco.

Pero antes de continuar con este debate y establecer nuestra postura teórica, es necesario realizar un análisis sobre los términos que hoy en día empleamos para referirnos a estos fenómenos que denominamos "presagio", "augurio", "prodigio" o, en los propios términos nahuas del siglo XVI, tetzáhuitl.

\section{¿Qué es un tetzáhuitl?}

Ya con anterioridad Miguel Pastrana Flores (2009: 21) se había percatado que el campo semántico del término tetzáhuit/ no corresponde plenamente al de las palabras castellanas, por lo que el autor, después de realizar un análisis en diversos vocabularios y textos, lo define como "algo inusitado, portentoso, que causa asombro, espanto y es anuncio de algún acontecimiento futuro" (Pastrana Flores, 2009: 23). En lo particular, comparto con el autor varias de estas definiciones, incluyendo la idea de que el tetzáhuit/ forma parte de la tradición indígena nahua y que bajo esta premisa es necesario analizarlo para entender su simbolismo dentro de los propios parámetros de la cultura náhuatl.

En una publicación previa (Hermann Lejarazu, 2019a: 84-85), llevé a cabo un análisis somero del término considerando algunos vocabularios y diccionarios del náhuatl en los que se registra el vocablo tetzáhuitl como un concepto análogo al término agüero. Por ejemplo, fray Alonso de Molina (2001: f. 111r) en su Vocabulario en lengua mexicana y castellana registra el significado de tetzáhuitl como "cosa escandalosa, o espantosa, o cosa de agüero.” Por su parte, Rémi Siméon (1977: 535) ofrece las entradas tetzauhqui, "espantoso, peligroso"; tetzauia, ninotetzauia, "ver una cosa como augurio, asustarse en extremo, estar escandalizado", 
o bien, tetzauhtéotl, "dios horrible, que espanta, y sobrenombre dado a Huitzilopochtli”.

Hoy en día, algunos autores como Frances Karttunen (1992: 236-237) registran tetzahuia como "estar rodeado o acosado por algo espantoso / espantar a otros, algo que augura un mal para alguien y tetzáhuitl es "algo extraordinario, espantoso, sobrenatural, un augurio o mal agüero". Para Federico Nagel Bielicke (2015: 172), tētzāhuih es una lexía verbal que puede componerse en las acepciones tētzāhuia, ninotētzāhuia, es decir, "asustarse, escandalizarse, ver como augurio". Así que tētzāhuitl es el nominal derivado que alude a "espanto, agüero" (Nagel Bielicke, 2015: 172).

En los textos de Sahagún (Códice florentino, t. III, lib. 12, cap. 1) no es difícil percatarse que la aparición del tetzáhuitl infunde miedo, espanto y sobrecoge al que lo mira o al que es testigo de una cosa maravillosa, sobre todo los que están relacionados con las premoniciones sobre la llegada de los españoles. No obstante, es necesario resaltar que el propio Sahagún en el manuscrito del Códice florentino nunca registra la palabra "presagio" en la columna del texto en castellano, sino que hace referencia a las "señales, pronósticos o agüeros" que acontecieron antes de la Conquista.

Sin embargo, hay un aspecto que quiero enfatizar sobre el significado del tetzáhuitl que no ha recibido mucha atención y me refiero, en particular, a lo que en el fondo entraña el tetzáhuit/ no como augurio en sí, sino como la aflicción o el miedo que siente la persona al sufrir el espanto: mo-tetzahuiani y el debido remedio que tenía que realizar el individuo para tener valor y superar sus temores, por lo que sólo así se estabilizaba su destino o se calmaban sus impulsos (Hermann Lejarazu, 2019: 84).

Creo que una clave para comprender al tetzáhuit/ se encuentra en el libro quinto del Códice florentino donde se describe de qué manera se manifestaba el "augurio" y al mismo tiempo lo que se tenía que hacer para no dejarse vencer por el miedo. Un ejemplo de ello se encuentra en el tetzáhuitl del gigan- te ("estantigua" en la versión castellana de Sahagún) que en la noche se aparecía o se dejaba ver para producir miedo en la gente y sembrar el temor de que quizá alguien moriría en la guerra. Pero, de acuerdo con Sahagún:

quien era esforzado, animoso, de destino endurecido, forcejeaba con el gigante, ya no lo dejaba huir y le pedía espinas para ser valiente en la guerra y tomar cautivos [...] En cambio, el cobarde se desmayaba, se le amortecía el corazón, ya no es dueño de su saliva, su paladar está bien seco [...] y huía del gigante para esconderse en su casa (López Austin, 1969: 51).

Por lo tanto, más que un augurio en sí, (como actualmente lo entendemos y que lo veremos más adelante en su significación latina) es interesante señalar que, en el fondo, el tetzáhuit/ representa el temor avasallante que sobrecoge al corazón, entumece el vientre y paraliza los sentidos, por lo que el horror que experimenta la persona que llega a presenciar el tetzáhuitl (mo-tetzahuia-ni, "el que se espanta", "el que sufre el espanto") puede llevarlo a la enfermedad y a la muerte, y eso es lo que constituye, desde mi punto vista, la esencia del tetzáhuitl, la esencia del augurio fatal: cuando la persona no enfrenta sus miedos o no busca la ayuda del tonalpouhque (sacerdote especialista que sabía interpretar los destinos), indubitablemente morirá, será presa de sus miedos y temores que lo enfermarán y lo llevarán a un destino fatal.

En un magnífico artículo, Alfredo López Austin (2019: 14-19) realiza una exhaustiva búsqueda en el Códice florentino para identificar los contextos en los que aparece la palabra tetzáhuitl en la magna obra sahaguntina, por lo que dicho análisis lo lleva a determinar en qué momento el término corresponde a un augurio o en cuál otro los significados son diferentes. Un aspecto importante que deriva de su estudio es que, en efecto, el concepto tetzáhuitl entraña elementos que no solamente refieren al augurio en sí, pues, por ejemplo, destaca el 
significado que tiene la palabra en los capítulos del libro tercero dedicados a la caída de Tula y a la huida de Quetzalcóatl. Según nos menciona este autor (López Austin, 2019: 16-17), las visiones, engaños o maleficios que provocan los hechiceros aparecen bajo la denominación de tetzáhuitl, aunque no necesariamente reflejan el mal que han provocado, pues sus actos se muestran como hechos portentosos, acciones de ilusionismo, agresiones directas o eventos que llevan a la muerte a todos aquellos que los presenciaron.

\section{¿Qué es un agüero, presagio o prodigio?}

En este apartado empleo ya los términos castellanos en los que suele ser traducido el concepto nahua tetzáhuitl, visto desde los textos de Sahagún o Molina del siglo XVI hasta lo realizado hoy en día por los autores contemporáneos.

La palabra castellana agüero proviene del latín augurium, derivado del nombre augur, es decir, el intérprete que es capaz de leer los mensajes divinos a través de signos escritos en el cielo.

En la Roma antigua, prácticamente desde sus orígenes, existía el Colegio de los Augures constituido por sacerdotes que podían interpretar los auspicios tras la consulta ritual del vuelo de los pájaros, el paso de los meteoros o de los fenómenos atmosféricos.

Los augures funcionaban como una corporación al servicio del estado romano, pues respondían a preguntas expresas de algún magistrado y en muchas ocasiones decidían el éxito o fracaso de una bataIla; eran los únicos autorizados para interpretar la voluntad de los dioses (Chevalier y Gheerbrant, 1986: 150). Por otro lado, el término presagio proviene del latín praesagium, "presentimiento", "presagio” y, quizá por conducto del italiano, la voz presagio, "adivinación, señal”, pasó a la lengua casteIlana (Corominas y Pascual, 1985: 643).

Pero esta jerga de términos en lengua española pareciera sólo indicar sutiles diferencias de significado entre "augurio", "pre- sagio", "prodigio"; no obstante, para Raymond Bloch (1968) sí existe una diferencia importante entre presagio-augurio y prodigio. De acuerdo con este autor, quien analizó a profundidad el papel de los presagios y prodigios en la antigüedad griega, romana y etrusca (Bloch, 1968: 101), el presagio u omen, omine, conlleva en sí el carácter del porvenir, pero es un porvenir cercano e inmediato en el cual se manifiesta una advertencia enviada por los dioses para apartar - acercar a los hombres de alguna acción o empresa en particular. Es posible que omen, argumenta este autor, en su significado más esencial o en el sentido primitivo de la palabra, pueda interpretarse como "declaración de verdad” (Bloch, 1968: 101), de ahí la importancia del término dentro del pensamiento religioso romano. Aunque, según Bloch, el hombre romano tenía plena facultad de aceptar o rechazar el mal augurio, o bien, transformarlo o conjurarlo mediante hábiles palabras que modificaran mágicamente su sentido (Bloch, 1968: 102).

El caso de los auspicia, como hemos visto, son signos dados por la observación del vuelo de las aves (avis, specio), pero esta práctica llevada a cabo por los augures se extendió a la interpretación de presagios diversos, como los rayos, relámpagos, apetito de los pollos sagrados, etcétera, por lo que los augures recogen los auspicios y, a través de un elaborado ritual, formulan la respuesta. Pero era necesario que existiera un ritual preciso, por lo que Bloch señala: "La ciencia augural estaba hecha de ritos y de fórmulas complicadas que regulaban hasta en sus menores detalles las ceremonias necesarias para la observación y la justa interpretación de los auspicios" (1968: 103).

La palabra prodigio, en cambio, tiene un origen y significados completamente distintos. En efecto, en la mentalidad romana el prodigio no es un signo que avisa sobre el porvenir inmediato o lejano, sino que es un fenómeno imprevisto, antinatural y terrible que expresa la cólera de los dioses acerca de alguna transgresión a los deberes religiosos que haya roto el equilibrio entre los hombres y los dioses (Bloch, 1968: 103). La 
diferencia entre ambos tipos de manifestaciones (presagios y prodigios) es fundamental para entender el comportamiento y la capacidad de respuesta del individuo romano, pues se establece un campo conceptual distinto que conlleva a un tipo específico de acción concreta que se debe ejercer para enfrentar el fenómeno. En palabras de Bloch,

presagios y prodigios no son signos que prefiguran el porvenir, separados solamente por su fuerza de intensidad o de fuerza anunciadora, sino que el presagio advierte al hombre que prosiga o detenga su empresa, mientras que el prodigio revela, por su parte, que se ha roto la paz con los dioses y que los individuos y la ciudad están gravemente amenazados por la cólera divina (1968: 104)

En pocas palabras, los signos divinos prefiguran dos elementos: primero, o es una advertencia leve y fugaz relativa a la empresa inmediata (el omen o el auspicium) o es, por otro lado, el prodigium que muestra tácitamente el enojo o cólera de los dioses, ya sea a través del rayo, el terremoto u otro fenómeno extraordinario que mueve las conciencias (Bloch, 1968: 105).

Finalmente, una conclusión interesante a la que llega este destacado latinista e historiador de la antigüedad romana es que, en su sentido primitivo, en la palabra prodigio no prefigura el porvenir, es decir, no hay nada en la significación prístina de prodigio que contenga una idea del presagio relativo al porvenir (Bloch, 1968: 106-107), por lo que queda claro que presagio y prodigio no tienen el mismo origen, ni el mismo sentido: "Esto está de acuerdo con el valor primitivo del prodigio en la mentalidad latina: es el signo terrorífico de la cólera de los dioses y suscita en el hombre un sentimiento de horror, un temblor que lo invade ante la intervención tangible de las fuerzas divinas. Pero no prefigura el porvenir".

1 Existen otros términos estrechamente vinculados a prodigium, como son ostentum, portentum, mostrum, miraculum, pero tampoco hay en ellos indicios relacionados al porvenir, pues en su significación primitiva ostentum y portentum designan un fenómeno extraor-
Este examen de términos que hemos realizado nos ofrece un marco conceptual adecuado acerca de los sentidos o significados que adquirieron los vocablos nahuas al ser traducidos por los lexicógrafos religiosos en el siglo XVI. Desde mi punto de vista, asumo la postura teórica de analizar con precisión el origen y significado de los términos empleados, aun por los cronistas y otros importantes misioneros, para discernir el sentido que el término tetzáhuitl ha tenido a lo largo del tiempo y que ha sido retomado por autores modernos. Como podemos percatarnos, el latín era la lengua que conocían y manejaban todos los religiosos que llegaron al Nuevo Mundo para realizar su obra evangelizadora, por lo que, a su vez, los textos y la historia latina fueron parte integral de su formación histórica y cultural. Es completamente razonable que el latín fuera el idioma modelo y conceptual del que se sirvieron los misioneros para lograr su magna empresa gramatical y lexicológica. De esta manera, términos y vocablos que remitían al pensamiento mágico-religioso de los grupos nahuas llegaron a ser identificados inmediatamente con la religión y el mundo clásico romano. Un ejemplo de ello es el famoso libro I de Sahagún en el que los dioses mexicas son comparados con deidades romanas al nombrarlos en su listado como "otro" Júpiter, Venus, Ceres, Vulcano, etcétera.

En un sentido estricto, el tetzáhuit/ no es un augurio, pues según hemos visto, este nombre sólo aplica a la agrupación o colegio de sacerdotes que únicamente tenía la función de consultar las señales celestes a petición expresa de un magistrado romano. De acuerdo con algunos autores (Chevalier y Gheerbrant, 1986: 150), el término augur refiere al intérprete de los dioses, pero cuya especialidad o función propia se da en el ámbito celeste. Por ejemplo, entre sus prácticas, el augur empleaba una vara o báculo

dinario de la naturaleza, pero de carácter inanimado; mostrum y miraculum aluden a una cualidad pavorosa de un ser vivo, pero en su sentido más antiguo, dichos términos no refieren a presagios (Bloch, 1968: 105-106), aunque en diccionarios modernos de latín sí se llega a configurar el concepto presagio bajo estas acepciones. 
que dirigía al cielo para dibujar o formar un templo cuadrangular en cuya circunscripción debía volar el ave o introducirse dentro de éste para llevarse a cabo la interpretación. Como hemos visto, entonces, la agrupación es en sí una institución estatal que responde a las necesidades del estado romano, por lo que sus respuestas se dan con un sí, o con un no, a una pregunta precisa del magistrado.

Hoy en día, por extensión, se aplica el término augurar o augurio a todo aquello que aparentemente muestra un indicio de algo que ocurrirá en el futuro, en donde ya nada tienen que ver las aves, como lo era en la práctica antigua romana, pues actualmente cualquier evento es interpretado como un signo augural. De ahí, entonces, que le damos una significación mucho más amplia a esta palabra y que hoy en día aplicamos a cualquier clase de signo en el que de alguna manera se quiere ejercer una adivinación.

No es difícil observar que este amplio sentido del término fue aplicado también por los frailes, pues resulta sencillo cotejar en las fuentes cómo Durán, Sahagún o Motolinía nombraban como "agoreros" (o aquel que adivina por agüeros) a los sacerdotes que tenían un tipo de especialidad ritual diferente como, por ejemplo, los que empleaban la magia o la hechicería. Un caso que ilustra lo que comentamos está en el libro XII (Sahagún, 1989: Cap. VIII, 826), cuando Hernán Cortés y sus huestes aún se encontraban en las costas veracruzanas:

Envió Motecuzoma a aquellos adivinos, agureros (sic) y nigrománticos, para que mirasen si podrían a hacer contra ellos algún encantamiento o hechicería para con que enfermasen o muriesen o se volviesen. $Y$ éstos hicieron todas sus diligencias como Motecuzoma les había mandado contra de los españoles; pero ninguna cosa les aprovechó ni tuvo efecto, y ansí se volvieron a dar las nuevas a Motecuzoma de lo que había pasado, y dixéronle que aquella gente que habían visto era muy fuerte [...] (Sahagún, 1989: 826-827).
En cambio, en el texto náhuatl del Códice florentino son muy distintos los apelativos que se emplean para referir a los especialistas rituales enviados por Motecuhzoma con el deseo de que influyeran con algún maleficio. En efecto, en el Códice se les denomina nanahualtin, tlaciuhque y tlatlacatecolo, cuyas prácticas rituales parecen muy distintas entre sí, pero que en el fondo podían ser ejecutadas indistintamente por uno u otro. Los nanahualtin o nahuales son aquellos que tienen la facultad de introducir una de sus entidades anímicas en animales o en otros seres de carácter sagrado; los tlaciuhque tenían facultades adivinatorias y su conocimiento se basaba en la interpretación de señales que aparecían en el cielo, como por ejemplo, los eclipses; los t/atlacatecolo u hombres-búho son una categoría cercana a lo que denominaríamos brujos, pero cuya actividad es perjudicial a los hombres, pues a través de la magia consiguen sus fines y propósitos que son dañinos a las personas (López Austin, 1967: 87-107).

Es interesante que algunas de sus prácticas rituales estén precisamente descritas en el capítulo 8 del libro XII, pues a través de ellas era la manera en que Motecuhzoma pretendía detener a los invasores: "[...] que quizá podrían usar su magia sobre ellos, lanzar sus hechizos sobre ellos, que quizá podrían soplarles, encantarlos, que podrían arrojarles piedras, que podrían con algunas palabras de hechizeros, de brujos (tlacateculotlatolli), encantarlos, que puedan enfermarse, que puedan morir, o a causa de eso, regresarse" (Anderson y Dibble, 2012: t. 12, Cap. VIII, p. 22). ${ }^{2}$

Por lo tanto, dichos especialistas parecen tener dominio sobre la magia, los hechizos (tlachihuia, Molina, 2001: 117v) o encantamientos y no tanto sobre los agüeros, en el sentido que ya hemos aclarado arriba. De manera que se observa el empleo del término agoreros por parte de los cronistas, en

2 Para preparar la cita, he tomado la traducción del náhuatl al inglés de Anderson y Dibble en Florentine Codex. General History of the things of New Spain, fray Bernardino de Sahagún. Book 12, The Conquest of Mexico. 
un sentido despectivo y generalizador de todas aquellas prácticas consideradas de hechicerías, cuando en realidad se trata de métodos rituales y augurales muy distintos entre sí.

\section{Tratamiento ritual de presagios y prodigios en la antigüedad romana}

Ya hemos comentado anteriormente sobre el tratamiento ritual que elaboraban los augures alrededor de una petición de consulta por parte del magistrado romano. Pero, sin duda, el tratamiento ritual que se elaboraba en torno a un prodigio es un claro ejemplo de la enorme preocupación del estado para conjurar o atajar el daño que repercutía en la sociedad la aparición de un fenómeno de tan extraña naturaleza.

En efecto, una de las características de la actitud del pueblo romano, sobre todo en la época de la República, es la sólida organización ritual destinada a la expiación del evento milagroso (Bloch, 1968: 111). Hay pocos ejemplos de sociedades antiguas que se tomaran tan en serio la procuración de purificar un prodigio que difícilmente pudieran igualar a los romanos. El estado se encargó de consolidar los medios para expiar los prodigios a tal modo, que pueden considerarse jurídicamente sólidos y religiosamente eficaces todas las ceremonias y procedimientos que se llevaban a cabo para tal fin. De acuerdo con Bloch, el individuo romano estaba tan preocupado por salvaguardar su libertad de acción, que surgieron procedimientos sagrados meticulosos que buscaban purificar la mácula de la presencia divina y que trataban de apartar los peligros, pues el estado tomaba rápidamente el control para realizar una intervención eficaz y que la vida política y militar de la ciudad retomara rápidamente su vida normal (Bloch, 1968: 139-146).

De manera muy resumida, explicaré los métodos que seguía la República romana para abordar la aparición de un prodigio y los tipos de ceremonias o rituales de expiación que se realizaban para disolver sus efectos en la población. El procedimiento de la procuratio prodigium consistía en diferentes pasos en los que se daba, de inicio, la constancia de que se había manifestado un prodigio. La observación de un prodigio podía realizarla desde un simple ciudadano hasta un magistrado o un sacerdote, incluyendo la figura del Pontífice máximo. Después, venía la nuntiatio, es decir, el aviso a los cónsules sobre la aparición del prodigio para que pudieran verificarlo. Un cónsul hacía un informe al Senado acerca del fenómeno observado, para después leer la relatio y procuraba presentar testigos que certificaran la aparición del prodigio. El Senado escucha, delibera y vota un decreto en donde declara encargarse de los prodigios en nombre del estado (suscipere prodigia), pero también podía negarse a admitirlo si no había suficientes testigos que reconocieran la autenticidad del prodigio. Si se aceptaba el prodigio, el Senado organizaba los actos para su expiación, previa consulta de los especialistas rituales en caso necesario (Bloch, 1968: 144-145).

$\mathrm{Si}$ los prodigios eran verdaderamente graves, el Senado podía dirigirse a los pontífices, a los libros sibilinos o a los arúspices (grupo de sacerdotes de origen etrusco que interpretaba las voluntades divinas por medio de la consulta de las vísceras de los animales) para que pudieran dar su opinión y comenzar así las ceremonias de purificación. Los rituales o ceremonias de expiación debían llevarse a cabo con la ejecución correcta de los ritos prescritos, ya que cualquier falla podría traer nefastas consecuencias para la vida pública, pues de acuerdo con Sánchez Sanz:

La celebración de cualquier tipo de sacrificio en la religión romana necesitaba, para su correcta realización, que se cumplieran ciertos requisitos, condiciones, y procedimientos indispensables en los que el más mínimo error implicaría, no solo la repetición completa del ritual (llamada instauratio), sino también la realización de una ceremonia de expiación (llamada piacula) para hacerse perdonar el agravio cometido ante la o las divinidades (2013: 18). 
Entre las ceremonias que se realizaban para la purificación del hecho prodigioso se encontraban desde los sacrificios de toros y vacas; las novendiale sacrum, fiestas de nueve días; las lustratio urbis, procesión purificadora que rodeaba con un círculo mágico el espacio que convenía limpiar de toda mácula y que se acompañaba con el sacrificio de diversos animales; las suplicaciones públicas, en las que participaba todo el pueblo en ceremonias compuestas de plegarias; o bien, los cantos y danzas de 27 doncellas que formaban coros para presentar ofrendas, entre otros (Bloch, 1968: 148-149; Obsecuente, 2008: 279).

Una de las fuentes romanas que con mayor detalle describen el proceso ritual en torno a la expiación del prodigio es Tito Livio, quien ofrece un cuadro muy completo sobre la gran ceremonia realizada en el 207 a.C. para garantizar el éxito de un nuevo ejército organizado por los cónsules Cayo Claudio Nerón y Marco Livio Salinator que se disponía a enfrentar la temible invasión cartaginesa durante la Segunda Guerra Púnica. ${ }^{3}$ Como se puede constatar en esta fuente, lo único que podía garantizar el éxito de la ceremonia y, desde luego, la venia divina, era el correcto y puntual cumplimiento de todas y cada una de las prescripciones reglamentadas en los manuales de los pontífices, pues la más mínima mácula o falla ínfima en el ritual repercutiría en el rechazo de la ofrenda por parte de las deidades (Sánchez Sanz, 2013: 18-20; Tito Livio, Lib. XXVII).

Brevemente mencionaremos que era de suma importancia para los pontífices, por ejemplo, tener el cuidado de escoger el tipo de animal que se sacrificaría (toros, bueyes, terneros). Sobre todo, que estuvieran sanos y de buena disposición, porque si había resistencia del animal, esto era visto como

\footnotetext{
3 Las guerras entre romanos y cartagineses (nombrados punicus por los romanos) se conocen como "Guerras Púnicas". El mundo mediterráneo se va a ver envuelto en una enorme crisis política y militar con la Segunda Guerra Púnica (217-202 a.C.) en la que Roma estuvo seriamente amenazada de ser atacada por Aníbal y sus ejércitos. La Segunda Guerra Púnica va a desatar toda una serie de cambios ideológicos en el pensamiento romano, sobre todo, en lo que se refiere a la manera de interpretar los prodigios.
}

una señal de mal agüero y, a su vez, se tenía especial cuidado de que el sacrificio no fuese demasiado cruento, es decir, que el animal muriese lo más rápido posible, porque si tardaba en morir o tenía sufrimiento, era señal de que el ritual no había sido elaborado adecuadamente y tenía que repetirse todo de nuevo. Finalmente, los arúspices se encargaban de examinar las entrañas para constatar que la ofrenda hubiera sido aceptada con beneplácito por los dioses, porque de lo contario, se tendría que repetir nuevamente, situación que ocurría muy a menudo según lo hace constar Tito Livio (Sánchez Sanz: 2013: 20).

\section{Tipo de prodigios que se manifestaban}

El tipo y número de prodigios que se encuentran registrados por Tito Livio, entre otras fuentes es, en verdad, muy numeroso e imposible de abordar en estudio tan breve como el presente, por lo que hemos recurrido al Libro de los prodigios de Julio Obsecuente para dar ejemplos de algunos de estos fenómenos portentosos. No se tienen muchos datos sobre este autor, pero se cree que pudo haber hecho la recopilación entre los siglos IV y $\mathrm{V}$.

En efecto, Julio Obsecuente tuvo acceso a las décadas de Tito Livio por lo que, de manera poco clara, llevó a cabo una selección de prodigios directamente extraídos de la obra del historiador latino. No son evidentes los objetivos del porqué haya realizado dicho trabajo, pero es interesante que de manera sistemática haya transcrito casi literalmente el texto original, aunque soslaya, significativamente, los ritos de expiación que para Livio son parte imprescindible del prodigio (Villar Vidal en Obsecuente, 2008: 271-282).

A manera de ejemplos, transcribiré los prodigios que se presentaron en los años 136, 135 y 134 a.C., en los que estuvieron a cargo diversos cónsules de acuerdo con el sistema político romano:

Prodigios en el Consulado de Lucio Furio y Sexto Atilio Sarrano: 
Regio fue devorada casi totalmente por un incendio sin que hubiera el menor indicio de haber sido intencionado o deberse a un descuido humano. De una esclava nació un niño con cuatro pies, manos, ojos y orejas y dos órganos sexuales. En Putéolos, en el balneario, manaron ríos de sangre. Fueron golpeados por el rayo muchos objetos. Por prescripción de los arúspices, el niño fue quemado y sus cenizas arrojadas al mar. El ejército romano fue aplastado por los vacceos (Obsecuente, 2008: 298-299).

Prodigios en el Consulado de Servio Flaco y Quinto Calpurnio:

El monte Etna despidió llamas mayores de lo acostumbrado. En Roma nació un niño sin ano. En Bononia nacieron mieses en los árboles. Se escuchó el canto de un búho primero en el Capitolio y después en las inmediaciones de la ciudad. Se ofreció una recompensa y el ave fue capturada por un cazador y quemada; sus cenizas fueron esparcidas por el Tíber. Un buey habló. En Numancia se llevó mal la campaña y el ejército romano fue aplastado (Obsecuente, 2008: 298-299).

Prodigios en el Consulado de Publio Africano y Gayo Fulvio:

En Amiterno se vio un sol durante la noche, y su luz fue observada durante bastante tiempo. Un buey habló y fue alimentado a expensas públicas. Llovió sangre. En Anagnia ardió la túnica de un esclavo y una vez extinguido el fuego no apareció el menor vestigio de las llamas. En el Capitolio, durante la noche, un ave emitió gemidos parecidos a los humanos. En el templo de Juno Reina fue alcanzado por el rayo un escudo lígur. En Sicilia estalló una revuelta de esclavos fugitivos tras ser sofocada una conspiración de esclavos en Italia (Obsecuente, 2008: 298-299).

Prodigios de los años 94 a.C. en los consulados de Gayo Celio y Lucio Domicio:

Se celebró un novenario sacro porque había llovido piedra en el país de los volscos [...] Na- ció, muerta, una niña con dos cabezas, cuatro manos y dos órganos genitales [...] En el país de los vestinos llovió piedra en una casa de campo. Apareció en el cielo un objeto incandescente y pareció que ardía todo el firmamento. Manó sangre de la tierra y se coaguló $[\ldots .$.$] En Fésulas se vio que caminaba entre$ los sepulcros durante el día, apilada, una gran multitud de gente vestida de luto, lívido el semblante (Obsecuente, 2008: 315).

Prodigios en el consulado de Gayo Valerio y Marco Herenio del 93 a.C.:

En Roma y en los alrededores fueron batidas por el rayo muchas cosas [...] En Arrecio sudó una estatua de Mercurio [...] El cónsul Herenio hizo una inmolación por dos veces y no encontró la protuberancia del hígado [...] En Volsinios, al clarear el día, se vio brillar una llama en el cielo; al condensarse en un solo punto, la llama presentó una abertura de color gris, dio la impresión de que el cielo se abría y por la hendidura aparecieron los extremos de la Ilama. La expiación, por medio de ceremonias de purificación, fue un éxito, pues el año fue tranquilo por completo tanto en el interior como en el exterior (Obsecuente, 2008: 316).

Desde luego, la lista de prodigios y los años en que ocurrieron es muy larga, pero es interesante que cada uno de estos prodigios debía ser tratado ritualmente para buscar la purificación de éstos, establecer el orden del mundo y aplacar la ira de los dioses, tal y como se menciona en el último prodigio del año 93 a.C., cuya expiación resultó exitosa y trajo tranquilidad a la ciudad de Roma y al resto de Italia.

De acuerdo con Bloch (1968: 89-90), entonces el prodigio es el fenómeno sagrado por excelencia. Es la irrupción de lo divino en el mundo natural pero su presencia, aunque fuese efímera, dejaba una mácula en la tierra. Los ritos de expiación, por tanto, están destinados a borrar la mácula peligrosa que dejó el contacto con lo sagrado y, por si fuera poco, el ritual buscaba calmar el sentimiento de horror que había dejado la experiencia divina. Es por esta razón que cuando 
el prodigio era demasiado ostensible, se había de convocar a los arúspices, pues eran los expertos no sólo en la exégesis de los prodigios, sino también en su extinción.

\section{¿Presagios o prodigios en el México antiguo?}

Establecidas las diferencias conceptuales entre augurio, presagio y prodigio, según lo hemos revisado en la antigua religión romana de la época de la República, y lo observado en el tratamiento que diversos cronistas y frailes del siglo XVI le dieron al término nahua tetzáhuitl para referirse a éste como augurio o presagio, creo que es posible determinar que existió una clasificación distinta al significado que realmente entraña este concepto en el pensamiento nahua. En efecto, creo que la comparación entre sociedades aparentemente tan distintas en el espacio y el tiempo nos ayuda, en realidad, a dimensionar mejor los aspectos en los que llega a manifestarse la respuesta ante una presencia divina. No nos parece forzada o fútil la comparación entre dos formas de pensar en cuanto a su aproximación a lo sagrado, pues el fenómeno de los presagios o prodigios se presenta de manera universal en muchas sociedades antiguas y modernas y cuyas apariciones perfilan o anuncian eventos extraordinarios que tendrán consecuencias en la vida normal de los hombres. Pero es de llamar la atención, como lo planteamos al principio de este artículo, que las respuestas ante la presencia divina se hayan efectuado desde posturas distintas.

Antes de analizar los elementos que creemos identificar en ambas tradiciones, es necesario aclarar que de ninguna manera negamos la arraigada creencia adivinatoria que caracteriza a la sociedad nahua de los siglos XV y XVI y en general a toda Mesoamérica. El pensamiento indígena orientado al devenir y al acaecer cotidiano con plena conciencia del mañana se halla perfectamente documentado no sólo en las crónicas e historias escritas por los misioneros o evangelizadores, sino también se encuentra expresada en los códices de tipo adivinatorio conocidos como Tonalpohualli, "cuenta de los días o cuenta de los destinos". De manera que la adivinación, a través de los diversos medios que se empleaban para pronosticar el curso de la vida y los destinos, era una de las prácticas más importantes del mundo mesoamericano (Boone, 2007: 19; Mikulska, 2015: 19 y 37).

Por ello, únicamente queremos matizar el significado augural de los tetzáhuitl que ha sido ponderado por numerosos cronistas, aspecto que indudablemente repercute en nuestra comprensión del papel de los llamados "presagios de la Conquista" y que queremos ponerlos en su adecuada dimensión histórica.

\section{Rituales de expiación}

Ya hemos referido, en páginas anteriores, las prácticas rituales de expiación que llevaron a cabo los romanos, de la época de la República, ante la revelación de un prodigio. Existió ahí un verdadero aparato público, religioso y político tan especializado que daba respuesta expedita a tales fenómenos de la naturaleza para conjurar, en la medida de lo posible, las repercusiones que tendría en la vida diaria de la comunidad dichos hechos fantásticos. La aparición de un prodigio revelaba el enojo, el descontento o inconformidad de algún dios en particular, o de los dioses en general, al considerarse que existía una falla o un ritual mal elaborado o algún otro error humano que motivaba la manifestación de la cólera divina a través de un prodigio.

Como ya hemos señalado, Bloch (1968: 106-107) considera al prodigio como el fenómeno sagrado por excelencia cuya presencia deja en el individuo un enorme sentimiento de horror, un temor que lo invade ante la experiencia tangible de las fuerzas divinas, por lo que sólo a través de rituales de purificación se puede ayudar a la persona a tranquilizar ese impacto.

Desde mi punto de vista, el tetzáhuitl comparte también estas características con el prodigio romano, pues el concepto indígena nahua señala la aflicción o el miedo que 
siente la persona al sufrir el espanto (motetzahuia-ni), por lo que había que buscar el debido remedio para tener valor y superar sus temores. Según vemos en el libro $V$ de Sahagún, la presencia de lo sagrado desataba el miedo y causaba la pérdida del espíritu, y a consecuencia de ello, la gente moría: "Y cuando estas fantasmas (tlacanexquimiIli, envoltorio de cenizas de un hombre) se aparecían a alguna gente baxa y medrosa, arrancaban a huir y perdían el espíritu de tal manera de aquel miedo, que morían en breve o les acontecía algún desastre" (Sahagún, 2000: Lib. V, cap. 12, 455).

A lo largo del capítulo $V$, queda claro que muchas de las apariciones de fantasmas, de gigantes, de animales y otros nahuales son manifestaciones de Tezcatlipoca, quien pone a prueba la valentía y el arrojo de toda aquella persona que se enfrenta al tetzáhuitl y no huye despavorido a protegerse. Pero es interesante que, aun para aquellos individuos que no manifiestan tal valor, hay oportunidad de curarse de ese espanto, y ello es mediante la consulta o intermediación del tonalpouhque, el especialista en los libros de adivinación, quien prescribe el ritual para atajar y vencer ese miedo. De acuerdo con lo que se menciona en el ya citado libro $\mathrm{V}$ :

Cuando esto le acontecía, enseguida iba a ver al intérprete de los destinos, allí le fortalecía las entrañas, lo saludaba, le decía: "estás necesitado, criado, esclavito, mancebo, hombre valiente; que en verdad buscas, solicitas que se te fortalezca el ánimo; para esto viniste; viniste a verte en el espejo; viniste a consultar el libro [...] Esfuerza tu corazón; pasa por encima de tu lloro y de tu tristeza. He aquí sólo en vano con esto te doy banderas, te cubro de papeles para curarte, para rodarte de remedios. Haz merecimiento, prepara rápidamente los papelitos; se hará tu sacrificio de sangre; compra toda clase de papeles, de copal, de hule, etcétera. Cuando hayas hecho esto y sepamos el día en que lo ofreceremos al que está en el borde del ombligo de la tierra, al que se está levantando, vendrás (López Austin, 1969: 21). ${ }^{4}$

4 Es interesante que en la sección en castellano del Códice florentino (la parte conocida comúnmente como la Historia General de las cosas de Nueva España) Sa-
Sin duda, este ritual que el tonalpouhque pide al afligido por el tetzáhuitl, es un ritual de expiación. Es un rito de purificación que lo lleva a remediar el temor que lo aqueja ante la manifestación de lo divino. El especialista lo mueve a superar sus miedos, a que se fortalezca su corazón, pues aparentemente el individuo nació en un signo que no le confiere fuerza, que no le ayuda a sobreponerse a sus temores, por lo que su destino es frágil, es susceptible al miedo y por lo tanto puede morir o enfermar gravemente. En sí, esto es en lo que consiste el tetzáhuitl, pone a prueba la valentía y la fortaleza del espíritu, pero es una prueba dura, difícil, que todos aquellos que no tengan un destino fortalecido, morirán sin remedio; por ello, más que un augurio, el tetzáhuitl es la aparición de un prodigio que estremece los sentidos, confunde el pensamiento y pone a prueba al individuo, por lo que sólo a través de un ritual puede conjurar esos temores y limpiar esa mácula que le dejó el contacto con la presencia divina.

\section{¿Cómo se interpretan los presagios de la Conquista?}

Un aspecto que hemos comentado y que desde luego nos llama la atención, es la total ausencia de rituales expiatorios en las famosas apariciones que enmarcan a los presagios vinculados a la Conquista de México. No solamente en los relatos de las ocho señales o pronósticos que menciona Sahagún hay una total ausencia de rituales de cualquier naturaleza sino también, incluso, en los presagios recabados por Motolinía, Durán o Torquemada. ¿Qué tipo de tetzáhuit/ fueron estos que no se buscó conjurarlos de alguna manera ante las enormes tribulaciones causadas a Motecuhzoma y a la población en general? ¿No fueron acaso señales

hagún menciona que el destinatario de la ofrenda de papeles y hule es Xiuhtecuhtli, el señor del fuego, nombre que no está expresado en el texto náhuatl, por lo que coincido con María José García Quintana (2004: 247-248): que es necesario hacer una comparación entre ambos registros colocados en la magna obra, pues Sahagún (2000: Lib. V, cap. 1: 449) añade información importante que complementa al texto original en náhuatl al ofrecer su versión o trasvase en español. 
divinas que demostraban alguna advertencia o manifestaban el porvenir (en el sentido que hemos analizado de augurio)?

Pienso que, indudablemente, cuando se comenzó a recopilar este tipo de relatos, el concepto de tetzáhuitl no fue comprendido en su dimensión exacta por los frailes, o bien hubo la intención de cambiar el sentido de las palabras. García Quintana (2004: 227) observa, atinadamente, que mientras la columna en náhuatl del libro $\mathrm{V}$ del Códice florentino se describen apropiadamente a "los intérpretes de los destinos, a los que se decían eran sabios [...]", la sección castellana de Sahagún, por el contrario, dice "agureros" cuando el misionero sabía de sobra que los tonalpouhque no eran únicamente "agoreros".

A su vez, se encuentra bien documentado, tanto en las obras de Sahagún como en las de Motolinía o Durán en general, que la aparición del tetzáhuitl relativo a la Conquista provocó la angustia de la gente de tal manera que todos quedaron escandalizados y que golpeaban sus labios con las manos (Alcántara, 2019: 58), tal y como debía causarlo cualquier tetzáhuitl.

Fray Diego de Durán menciona reiteradamente, de manera semejante como lo registra Sahagún, que Motecuhzoma se encontraba abatido, invadido por el miedo y paralizado, del mismo modo que a aquellos individuos a los que se les presentaba un tetzáhuitl como el del gigante o el envoltorio de cenizas, según lo explica el libro $\vee$ ya comentado. De acuerdo con Durán: "Era el sosiego de Montezuma tan poco y traía tan sobresaltado su corazón, que todas las veces que veía la cometa, o que oía el alarido que los indios daban al tiempo que salía, que no podía quietar su corazón ni sosegar su pecho, dado que fuese animoso y de gran virtud" (Durán, 2002: I, 560).

Ante tales apariciones o hechos prodigiosos, cómo es posible que no tengamos registradas en las fuentes algún tipo de respuesta ritual o ceremonial para conjurar tales portentos. ¿No existía, entonces, al menos en la gran ciudad de Tenochtitlan, la menor intención de atajar o purificar el prodigio? Desde mi punto de vista, pueden considerarse dos respuestas: la primera es que no existieron ceremonias de naturaleza semejante a las ya identificadas en la antigua Roma, de manera que no existía una respuesta ritual definida o establecida para enfrentar o conjurar al tetzáhuitl que tenía un fuerte impacto colectivo; a diferencia de lo que hemos visto en el libro $\vee$ de Sahagún, en donde el tetzáhuit/ tenía un carácter individual, más directo e inmediato para la persona que lo sufría y que actuaba directamente sobre el quehacer cotidiano del hombre. O bien, número dos, que el mundo nahua tenía una percepción muy distinta del tetzáhuitl de la que en realidad nos quieren hacer creer las fuentes escritas por los misioneros, por lo que más bien, dichos relatos no se configuraron originalmente como presagios o augurios, sino que éstos transitaron por diversas etapas de construcción hasta su elaboración final como agüeros que anunciaban la llegada de los españoles.

En cuanto a la primera consideración, es decir, la ausencia de rituales expiatorios en el mundo mesoamericano, nos conlleva a revisar, teóricamente, si todos los rituales a nivel universal deben cumplir con los mismos pasos o procedimientos técnicos para saber si se cumplen, o no, las condiciones para definir la existencia de un ritual expiatorio, sea cual fuera la sociedad o grupo que lo practicó; condición que, naturalmente, excede los límites de este trabajo.

No obstante, cualquier observación somera a las fuentes mismas nos revela que sí existieron en el mundo nahua rituales de naturaleza semejante a las que hacemos alusión, pues, por ejemplo, nuevamente retomando los capítulos del libro XII del Códice florentino, cuando los mensajeros enviados por Motecuhzoma regresaron de su primera entrevista con Cortés después de estar dentro de los barcos, el señor de México no los recibió sino hasta después de que se sacrificaran a varios individuos y rociaran con su sangre a los mensajeros. Entonces, en el Coacalli "los mensajeros fuéronse a la sala, y también Motecuzoma se fue allá. Y allí delante de los mensajeros mataron los capti- 
vos y rociaron a los mensajeros con sangre de los captivos. Hicieron esta ceremonia porque habían visto grandes cosas, y habían visto a los dioses y hablado con ellos" (Sahagún, 1989: Lib. XII, Cap. 6, 825).

Indudablemente, se trata de un ritual de purificación, pues los mensajeros al haber estado en contacto con algo completamente desconocido, algo sobrenatural y peligroso, les había dejado una mácula que era necesario limpiar, pues había sido una experiencia con lo sagrado que solamente a través de un ritual de expiación era posible borrar. De ahí que Motecuhzoma sólo accedió a verlos después de que los purificaran con la sangre de los sacrificados, a pesar de que le urgían las noticias del encuentro con aquellos extraños.

Por esta razón, pienso que sí existían rituales de expiación semejantes a los romanos, pues el acercamiento a lo sobrenatural y lo sagrado igualmente requería de acciones inmediatas que marcaran una separación o cura ante el prodigio manifestado. Aunque, desde luego, no tenemos referencias o menciones en las fuentes del centro de México sobre la existencia de un aparato estatal de tal estructura y mecanismos, como el romano, que se encargara de las ceremonias y rituales necesarios para conjurar tales prodigios. Por ello, la llegada de los españoles a tierras mesoamericanas fue tan sorpresiva como la aparición de cualquier tetzáhuitl o prodigio que movió las conciencias y sobresaltó el corazón y los sentidos.

Por lo tanto, pienso que, en realidad, el discurso de las premoniciones preparadas y presentadas por Sahagún en el primer capítulo del libro XII conforman una sección aparte y descontextualizada del resto de la elaboración de los capítulos. En ningún otro párrafo de la "Historia de la conquista" se vuelve a hacer alusión a los presagios, no se vuelve a tocar el tema ni siquiera en los momentos más neurálgicos de la narración, por lo que no nos queda duda que tales prodigios forman parte de una tradición a posteriori que tuvo lugar tras los sucesos de la guerra. Es muy probable que la construcción de este nuevo género discursivo haya recogido diversas tradiciones en torno a los tetzáhuitl, sobre todo en lo que se refiere al "que se espanta, al que sufre el espanto", pero que mucho tiempo después se transformaron en el tetzáhuitl que anunciaba la llegada de extrañas gentes. De esta manera, en esencia, lo único que se conservó del sentido antiguo del tetzáhuitl como prodigio es el efecto que produce en el ánimo y el corazón de la gente, pues tales eventos extraordinarios revelan la presencia divina en la tierra.

\section{Conclusiones}

Creo que, a lo largo del presente artículo, hemos tratado de exponer una serie de investigaciones y reflexiones en torno al significado del tetzáhuit,, no tanto como un augurio o presagio sobre la llegada de los españoles, sino que, fundamentalmente, nos hemos preocupado en analizar el sentido intrínseco del término náhuatl que entraña un sentimiento de temor, miedo y angustia ante la presencia de lo divino. Esta manifestación de lo sagrado irrumpe en la vida cotidiana de las personas y, a nivel individual, conforma un reto que debe ser superado por quienes tienen un signo o tonalli no fortalecido, no capaz de enfrentar sus miedos y que huyen ante la presencia de eventos extraordinarios u horrorosos que producen miedo y paralizan los sentidos.

Por ello, analizamos también la manera en cómo se encaraba en otras sociedades antiguas, como la romana del período de la República, por ejemplo, la presencia de lo divino y todo aquello que evidenciara el enojo o la ira de los dioses ante una falta ritual o una falla en las ceremonias que pudiera haber ofendido a una deidad. Si bien nos parece haber identificado cierta afinidad en los conceptos de prodigio y tetzáhuitl, sobre todo en su acepción de "irrupción de lo divino en el mundo natural o fenómeno sagrado que suscita en el hombre un sentimiento de horror ante la intervención tangible de las fuerzas divinas", considero, por otra parte, que lo que ocurría en el mundo indígena no era tanto por alguna ofensa o falla en el 
tratamiento ritual, sino porque Tezcatlipoca realmente ponía a prueba el valor y la fortaleza de algún individuo cuyo signo del día o tonalli no evidenciaba fuerza o arrojo ante los momentos de mayor peligro. De esta manera, cualquier manifestación de lo sagrado, ya sea animal, nahual o ser espantoso, debía ser encarado y vencido, porque de lo contrario, el individuo podía morir a menos que el prodigio fuese conjurado a través de algunos rituales que estuvieran dirigidos expresamente por el tonalpouhque.

¿Cómo podemos explicar la irrupción de un tetzáhuitl a nivel colectivo, cuya evidente manifestación asustaba y ponía en peligro la fortaleza de toda una ciudad? Creo, sin duda, que las primeras noticias sobre el desembarco de Cortés, o incluso, la información que se derivó del avance de las huestes invasoras dentro del territorio mesoamericano, debieron ser el mayor y más aterrador tetzáhuitl que pudieron experimentar no sólo colectivamente Motecuhzoma y Tenochtitlan, sino toda la población indígena en general. De acuerdo con el Códice florentino, el verdadero miedo y espanto que experimentó Motecuhzoma no fue tanto por la aparición de los presagios, sino por la inminente llegada de Cortés a las puertas de la ciudad capital. Me parece, en general, que se ha sobredimensionado el papel de los augurios o presagios de la Conquista, cuando en realidad, de haberse manifestado éstos, no debieron haber causado mayor impacto en la población que los primeros ataques de los españoles.

Sin duda, muchos años después de los trágicos eventos de la guerra de Conquista, se comenzó una revaloración o una autoexploración para entender qué había pasado con la llegada de esa gente extranjera. La tradición antigua que sobrevivió a la sacudida de esa guerra, y la labor evangelizadora que comenzaron a realizar los frailes para valorar la Conquista y legitimar la llegada de una nueva religión, ubicaron rápidamente en el tiempo las causas y razones de la caída de los antiguos imperios, y cómo estas señales en el cielo enviadas por los dioses o, por Dios mismo, fueron las advertencias acerca del final de un reinado entero. Todo ello, para el pensamiento de la primera mitad del siglo XVI, eran hechos históricos que podían verificarse en los textos y autores de la antigüedad.

Es bastante probable que la interacción entre los misioneros, que escribían la historia indígena, y los sabios y conocedores que habían sobrevivido a la Conquista, hubiesen tenido un fructífero diálogo e intercambio para explicarse lo sucedido. Con esta visión en mente, los prodigios cobraron su significación histórica y se volvieron relatos o géneros discursivos que explicaban el porqué de las cosas. Si observamos con detenimiento, los prodigios ocurridos a nahuas y romanos no son realmente distintos, sino que son parte de marcos universales que se repiten o que fueron duplicados conscientemente en el tiempo: tanto en Roma como en Tenochtitlan cayeron rayos, se incendiaron templos o personas sin causa aparente, aparecían resplandores o grandes llamas en el cielo, existieron aves, pájaros, búhos - lechuzas que cantaban, o se oían gritos y sollozos desde diversos lugares, y aparecían cometas amenazantes que surcaban el cielo (aunque desde luego existieron prodigios particulares propios de la cultura que los forjó), pero en el fondo, lo que realmente se rescata de los estudios comparativos son las diferencias que se establecen entre ambos fenómenos.

En efecto, mientras que para los romanos (siglos III-II a.C.) era imprescindible llevar a cabo grandes ceremonias para sacudirse la mácula dejada por la presencia divina, para el mundo nahua del siglo XV-XVI bastaba, al parecer, el ritual individual o la consulta de los códices para conjurar el prodigio, pues a nivel colectivo, no parece que se hubiesen manifestado presencias divinas que alteraran el orden natural de las cosas. De hecho, es interesante que, en los códices nahuas coloniales, el registro o constancia de prodigios es muy escaso en los años inmediatamente anteriores a la Conquista. En pictografías como el Códice Aubin, el Códice Mexicanus o el Manuscrito 40 de la Biblioteca Nacional de Francia, existen pocos 
tetzáhuitl, cuyo análisis rebasa los objetivos de este trabajo, pero sin duda, eventos como hambrunas, granizadas o epidemias, debieron constituir hechos notables en los registros históricos. Esta respuesta ante lo sagrado tuvo, entonces, prácticas rituales diversas, pues si recordamos los espantosos presagios que fueron vistos en la Inglaterra medieval del siglo VIII, donde se manifestaron inmensos remolinos de viento, destellos de relámpagos y flameantes dragones que volaban por los aires, según la Crónica anglosajona (Hermann Lejarazu, 2019b: 80-81), indudablemente, los monjes del monasterio de Lindesfarne debieron recurrir a numerosas plegarias, rezos y un sinfín de misas para atajar el inminente peligro que se les avecinaba: el ataque vikingo que diezmó numerosas poblaciones y conventos en las costas inglesas de aquella época.

\section{Fuentes consultadas}

Aimi, Antonio (2009), La "verdadera" visión de los vencidos. La Conquista de México en las fuentes aztecas, Alicante, Publicaciones de la Universidad de Alicante.

Alcántara, Berenice (2019), "Signos de final de los tiempos. Los ocho presagios de la Conquista en el Códice Florentino", en Arqueología mexicana, Los presagios de la Conquista de México, Tetzáhuit/, México, Editorial Raíces, pp. 5469.

Anderson, Arthur J.O. and Dibble, Charles (2012), Florentine Codex. General History of the things of New Spain, fray Bernardino de Sahagún. Book 12. The Conquest of Mexico, traducido del náhuatl al inglés con notas e ilustraciones por Arthur J. O. Anderson y Charles Dibble, segunda edición revisada, Salt Lake City, Utah, The University of Utah Press, p. 22.

Bloch, Raymond (1968), Los prodigios en la antigüedad clásica, Buenos Aires, Paidós.
Boone, Elizabeth Hill (2007), Cycles of Time and Meaning in the Mexican Books of Fate, Austin, University of Texas Press.

Carrasco, David (2000), Quetzalcóatl and the Irony of Empire. Myth and Prophecies in the Aztec Tradition, edición revisada, Boulder, University Press of Colorado.

Códice florentino (1979), edición facsimilar del manuscrito 218-220 de la Colección Palatina de la Biblioteca Medicea Laurenziana de Florencia, México, AGN, 3 vols.

Corominas, Joan y Pascual, José Antonio (1985), Diccionario crítico etimológico castellano e hispánico, vol. IV, Madrid, Gredos.

Chevalier, Jean y Gheerbrant, Alain (1986), Diccionario de los símbolos, México, Herder.

Durán, fray Diego de (2002), Historia de las Indias de Nueva España e islas de Tierra Firme, México, Conaculta, 2 vols.

Elliot, John H. (2010), "El derrocamiento de Moctezuma II y de su imperio", en Leonardo López Luján y Colin McEwan (coords.), Moctezuma Il. Tiempo y destino de un gobernante, México, INAH, pp. 218-235.

Florentine Codex (2002), General History of the things of New Spain, fray Bernardino de Sahagún. Book 12, The Conquest of Mexico, traducido del náhuatl al inglés con notas e ilustraciones por Arthur J. O. Anderson y Charles Dibble, segunda edición revisada, Salt Lake City, Utah, The University of Utah Press.

García Quintana, María José (2004), "La traducción de Sahagún del Libro $V$ del Códice florentino", Estudios de Cultura Náhuatl, núm. 35, México, UNAM-IIH, pp. 225-249.

Graulich, Michel (2014), Moctezuma. Apogeo y caída del imperio azteca, México, Ediciones Era/INAH/Conaculta. 
Hermann Lejarazu, Manuel A. (2019a), "El tetzáhuitl o agüero en los códices coloniales del Centro de México", Arqueología mexicana, 27 (158), México, Raíces, pp. 84-85.

Hermann Lejarazu, Manuel A. (2019b), "Presagios de conquista en anales y crónicas europeas", Arqueología mexicana, 27 (159), México, Raíces, pp. 80-81.

Johansson, Patrick (2013), "Presagios del fin de un mundo en textos proféticos nahuas", Estudios de Cultura Náhuatl, núm.45, México, UNAM-IIH, pp. 69-147.

Karttunen, Frances (1992), An analytical dictionary of náhuatl, Norman, University of Oklahoma.

Ledesma Bouchan, Patricia (2019), "Presentación”, Arqueología mexicana, Los presagios de la Conquista de México. Tetzáhuitl, México, Editorial Raíces, pp. 8-16, (Edición especial, 89).

León-Portilla, Miguel (1991), "Profecías y portentos en vísperas de la Conquista", en Leopoldo Zea (compilador), Ideas y presagios del descubrimiento de América, México, FCE, pp. 53-82.

Livio, Tito (2008), Períocas. Períocas de Oxirrinco. Fragmentos, y Julio Obsecuente, Libro de los prodigios, introducción, traducción y notas de José Antonio Villar Vidal, Madrid, Editorial Gredos.

López Austin, Alfredo (2019), "Las señales. La palabra tetzáhuitl y su significado cosmológico", Estudios de Cultura Náhuatl, núm. 57, México, UNAM-IIH, pp. 13-29.

López Austin, Alfredo (1969), Augurios y abusiones, introducción, versión y notas, México, UNAM-Instituto de Investigaciones Históricas.

López Austin, Alfredo (1967), "Cuarenta clases de magos del mundo náhuatl", Estudios de Cultura Náhuat, núm. 7, México, UNAM-IIH, pp. 87-117.
Magaloni, Diana (2016), Albores de la Conquista, México, Artes de México/Secretaría de Cultura.

Martínez Baracs, Rodrigo (1998), "Contactos y presagios", Historias 40, México, Revista de la Dirección de Estudios Históricos del INAH, pp. 29-34.

Mikulska, Katarzyna (2015), Tejiendo destinos. Un acercamiento al sistema de comunicación gráfica en los códices adivinatorios, México, El Colegio Mexiquense, A.C./Universidad de Varsovia.

Molina, fray Alonso de (2001), Vocabulario en lengua mexicana y castellana y castellana-mexicana, México, Porrúa.

Nagel Bielicke, Federico B. (2015), Diccionario del idioma náhuatl, México, UNAMFES Acatlán.

Obsecuente, Julio (2008), Libro de los prodigios (ver Livio, Tito).

Olivier, Guilhem (2006), "Indios y españoles frente a prácticas adivinatorias y presagios durante la Conquista de México", Estudios de Cultura Náhuatl, Vol. 37, pp. 169-192.

Olivier, Guilhem (2019), "Tetzáhuitl: Los presagios de la Conquista de México", Arqueología mexicana, Los presagios de la Conquista de México, Tetzáhuitl, México, Editorial Raíces, pp. 28-52.

Pastrana Flores, Miguel (2009), Historias de la conquista. Aspectos de la historiografía de tradición náhuatl, México, UNAM.

Rozat Dupeyron, Guy (2002), Indios imaginarios e indios reales en los relatos de la conquista de México, Xalapa, México, Universidad Veracruzana, INAH/BUAP.

Sahagún, fray Bernardino de (2000), Historia general de las cosas de Nueva España, 3a. ed., estudio introductorio, paleografía, glosario y notas de Alfredo López Austin y Josefina García Quintana, México, Conaculta, 3 vols. (Cien de México). 
Sahagún, fray Bernardino de (1989), Historia general de las cosas de Nueva España, $2^{\text {a. }}$. ed., estudio introductorio, paleografía, glosario y notas de Alfredo López Austin y Josefina García Quintana, México, Conaculta/Alianza Editorial Mexicana, 2 vols. (Cien de México).

Sánchez Sanz, Arturo (2013), "Prodigios y ceremonias de expiación en el año 207 a.C.", Iberian, Revista digital de historia, arqueología e historia del arte, núm. 6, enero-abril, pp. 14-26. <https://bit.ly/ 3agFjkt>, 22 de octubre de 2020.

Siméon, Rémi (1977), Diccionario de la lengua náhuatl o mexicana, México, Siglo $X X I$.

Recibido: 22 de diciembre de 2020. Reenviado: 30 de diciembre de 2020. Aceptado: 26 de enero de 2021.

\section{Manuel A. Hermann Lejarazu}

Doctor en Estudios Mesoamericanos por la UNAM. Profesor-Investigador de tiempo completo en el Centro de Investigaciones y Estudios Superiores en Antropología Social (CIESAS)-Ciudad de México y en la UNAM. Miembro del Sistema Nacional de Investigadores, nivel II. Sus líneas de investigación actual son la historia indígena de la Mixteca; iconografía y análisis de fuentes pictográficas (códices, mapas y lienzos) y la investigación interdisciplinaria entre geografía, historia y arqueología. Entre sus publicaciones más recientes se encuentran, como autor: "El entorno simbólico territorial del Mapa de Teozacoalco: representación del paisaje y sus linderos", Anales de Antropología 53 (2), México, Revista del Instituto de Investigaciones Antropológicas UNAM, pp. 11-27, (2019); el capítulo "Pueblo del quetzal o Río del quetzal: ¿Lugar de origen de los señores de Zaachila?", Arqueología y arte de los zapotecos antiguos, Vicente Cruz (coord.), Oaxaca, CICEAZ/Ayuntamiento de Zaachila (2019); coordinador del libro Señoríos mixtecos: su dimensión histórica, geográfica $y$ territorial, México, El Colegio Mexiquense, A.C. (en prensa). 


\section{Libro gujnto}

hechuma vo ugatas porgue ni podia cotrer, nj: midar : no perf(and obre cofa mas degue algund dofgrm cia le silfa de vents, por zason ded mal aguero que aria oydo : come cania lugge a torres, gue te auga de verpo verformedad, d muerke,

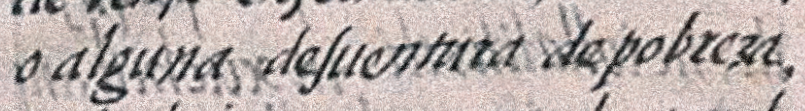

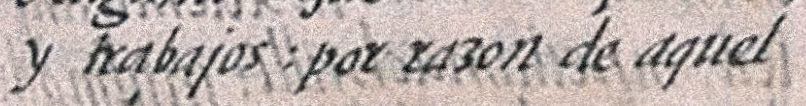
mil agricro.

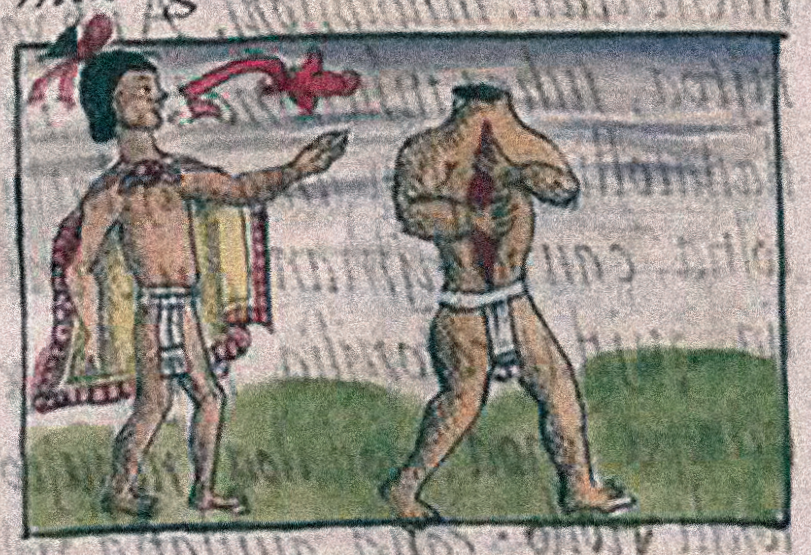

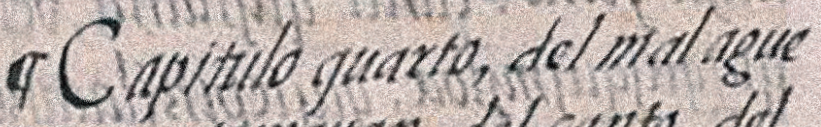
ro: gue fomasian def cents def buhd are.

\section{a. ambior, guatiodo dyan intax} al butio, efros naturates desfor inse un cspinta: tomaurth ninlaguete,

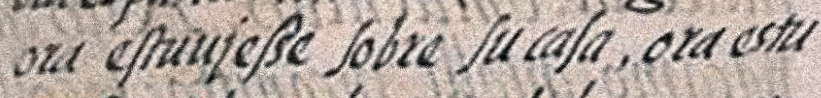
uesse fobre algun tit bol cerar: oy ondo aquella inancer idel cants dal buther Hugea ve atumorisuman,y prorlefticatun: gue alferm mal les aupa Jeveriz a de enformedad,o de mincte, oque fe los auja aur mo ikjn, amo iksikin, inmouhan flacitl: amocon vel ana, antijo quj caquij, can icampe on Hacuccule ilaxon, ontlactrectuech cioa : amo vel quifoca, can onciammiguj, on Moc aubraneguj, mjmiqui injna caio, ,a vitica chachapantiub, a iocmo vel nenemj: is qujmati in can oqujtersay ioaltepristi, can ica ormocacaiculb, ica ommaul th: aco cocolisti, miquilustis:anoco icnoort, tlactijut, thatlaculli, ino qujmacac: injcogujmothac

TI crauj capitulo, vnican mj ton: interanujt inje morebauja in, injginac fecrulut cbocain.

No

yoall netesalishin, tha tebaujaia, tekammachoia, inte culut choca:injquac taaca y tlapantenco, anoco ixacaltricpac, inuaub ticpac chocatica: inqujea quy quifotica: fecolo, o, o, tecoloo $0, y$ vin incagulsh, inchoca. Quy ton injquac in racoia, quinextial 